\title{
Assisted Living as a New Place Schema
}

\section{A Comparison With Homes and Nursing Homes}

\author{
Çağrı Imamoğlu \\ Bilkent University
}

\begin{abstract}
This study examines how the new place type of assisted living is represented in terms of its visual and verbal attributes and in comparison with the wellestablished schemata of home and nursing homes. Ninety-eight respondents (with a mean age of 62 years) are surveyed. Results indicate that home and nursing home are conceived in opposite terms, whereas assisted living is represented in between but with more homelike than institution-like attributes, except for its visual representation, which seems to involve rather institutionlike exteriors and undifferentiated interiors. Results are discussed with regard to basic attributes of assisted living and possible differences between schemata of newly developing and well-established place types.
\end{abstract}

Keywords: place schema; assisted living; nursing home; home; homelike and institution-like place attributes

\begin{abstract}
A schema can be defined as "a cognitive structure that represents knowledge about a concept or type of stimulus, including its attributes and the relations among those attributes" (Fiske \& Taylor, 1991, p. 98). As such, schemata serve to facilitate top-down cognitive processes based on one's prior knowledge, as opposed to bottom-up or data-driven processes, based on the specific characteristics of situations or people. Accordingly, schemata influence all aspects of one's cognitive and affective processes, as for
\end{abstract}

\footnotetext{
Author's Note: The present study is based on a doctoral study conducted at University of Wisconsin-Milwaukee. I express my thanks to Professor Jerry Weisman for his guidance, to the Fulbright Research Commission, Turkish Science and Research Council, and the Graduate School of University of Wisconsin-Milwaukee for providing partial financial support, to Professor E. Olcay Imamoğlu, and to two anonymous reviewers for their comments on an earlier draft of this article. Please send correspondence to Çağrı Imamoğlu; e-mail: icagri@ bilkent.edu.tr.
} 
instance, encoding, memory, inferences, and evaluations (Fiske \& Taylor, 1991). However, people's schemata have been studied mostly with regard to their social worlds involving persons, roles, self, and events, whereas studying place schemata has been generally neglected. In the present study, I aim to increase understanding of a particular type of place schema-assisted living - which I believe is important for two reasons. First, assisted living represents an important living alternative for older adults (C. Imamoğlu \& Imamoğlu, in press; Schwarz, 1999), so an increased understanding of people's conceptions of this place alternative may be valuable. Second, because assisted living represents a relatively new place type, exploring people's schemata regarding assisted living facilities in comparison to those of home and nursing homes may increase understanding of possible differences between newly emerging and well-established place types. Below, some background information on assisted living facility as a living alternative for older adults is introduced. Then the questions addressed in the present article are presented.

\section{Emergence of the Assisted Living Facility}

In today's world, accommodation needs of older adults seem to constitute a major problem. With the increasing life expectancies and changing lifestyles, it has become difficult to provide homecare to the aging family members who often have special needs. Even when families are willing to make sacrifices to give their loved ones a better life, they can hardly provide them the opportunities to socialize and participate in daily events because of heavy work schedules. The initial solution, the nursing home, was unable to answer the multidimensional needs of older adults sufficiently (French \& Mosher-Ashley, 2000; E. O. Imamoğlu \& Imamoğlu, 1992; E. O. Imamoğlu \& Kılıç, 1999; Johnson \& Grant, 1985; Kane, 2001; Schwarz, 1999). In fact, the efficiency-oriented medical model, on which the nursing home was based (e.g., involving routine, regulation, restriction), is often seen as directly clashing with the goals (e.g., providing privacy, autonomy) of a long-term care environment (Schwarz, 1999). Thus, there is an increasing need to provide alternative means of accommodation for the aging population.

From a realization of the problems of nursing homes emerged a new place type (i.e., assisted living), which has varying forms and labels, as for example, board and care homes, personal care homes, group homes, or close care. Although of varying forms, assisted living facilities in general 
were designed to meet two objectives with respect to long-term care. The first one involves flexibility of care, meeting the needs of individuals with differing levels of disabilities. In line with this objective, Kane and Wilson (1993) defined assisted living as "any group residential program that is not licensed as a nursing home, that provides personal care to persons with need for assistance in the activities of daily living (ADL), and that can respond to unscheduled needs for assistance that might arise" (p. xi). The second objective involves creation of a more homelike environment that promotes such attributes of place experience as resident privacy, independence, social interaction, and the like (Brummett, 1997; Regnier, 1994; Schwarz, 1999). For instance, in her model of assisted living, Wilson (1990) identified six such attributes involving privacy, dignity, choice, independence, individuality, and homelike surroundings. Thus, the concept of home would be expected to form the conceptual foundation of assisted living. The demand from residents' families is also pushing providers to change existing settings to reflect a homelike quality, and many assisted living facilities claim they provide service in residential settings (Schwarz, 1999). In fact, related studies, though few in number, have provided support for assisted living as a favorable living alternative for older adults (e.g., Ball et al., 2000; Dobbs, 2004; C. Imamoğlu \& Imamoğlu, in press; Zavotka \& Teaford, 1997).

Although there seems to be an assertion in the related literature to provide a homelike place (e.g., Ball et al., 2000; Brummett, 1997; Dobbs, 2004; Regnier, 1994; Wilson, 1990), it is not known to what degree this goal is actualized because home refers not only to a place type but also to a special relationship between people and the physical environment. Therefore, because of the complex personal nature of the concept of home, it may be difficult to transfer its components to a new place type. Hence, it is not clear whether assisted living is conceived by the public as a homelike place.

In fact, a New York Times article (Steinhauer, 2001) stated that the public did not know how to compare assisted living facilities and what to expect from them, perhaps suggestive of an underdeveloped conceptualization of the place type. In a similar vein, it has been claimed that the term assisted living is "ambiguous, confusing and controversial" (Schwarz, 1999, p. 190). For instance, it is not clear whether assisted living represents a place type or a level of care, and many researchers and groups admit difficulty defining it (e.g., The Assisted Living Workgroup, 2003; Mollica, Wilson, Ryther, \& Lamarche, 1995).

Thus, assisted living facilities, on one hand, are referred to as providing emotionally acceptable alternatives for older adults (e.g., Zimmerman, 
2000); on the other hand, concerns are being expressed about assisted living facilities turning into "mirror images of nursing homes" (Steinhauer, 2001) or "becoming mini-nursing homes" (Zahn, 2001), hence, pointing to some ambiguity about how assisted living is conceived by the public. The aim of the present study was to increase understanding of how assisted living is conceived by studying the attributes along which it is represented as compared to those of home and nursing homes.

\section{Main Questions Addressed}

The present study aimed to investigate verbal and visual attributes of assisted living in accordance with the related literature on living environments for older adults. Specifically, the questions addressed were the following: (a) What attributes are generally associated with assisted living, home, and nursing home? (b) To what degree do people's conceptions of assisted living differ from those of home and nursing home in terms of verbal (e.g., spatial-behavioral descriptions) and visual (e.g., interior and exterior images) attributes representing homelike and institution-like places? (c) What are the basic dimensions of the attributes through which assisted living facilities are represented?

Accordingly, in the first part of the study, attributes freely associated with assisted living, home, and nursing home were explored. In the second part, respondents' ratings of assisted living, home, and nursing home were compared in terms of (a) spatial-behavioral place descriptions representing homelike or institution-like places and (b) photographs representing homelike or institution-like interiors and exteriors. In the third part, which focused only on assisted living, basic dimensions of attributes along which assisted living is conceived were explored, using a set of place attributes to achieve a better understanding of this new place schema.

\section{Method}

\section{Sample}

Ninety-eight respondents (72 females, 26 males), with a mean age of 62 years, participated in the study. Respondents were recruited from senior resource centers, retired persons' groups, Community Opportunities Club for the disabled, Milwaukee County Department on Aging staff, University of Wisconsin-Milwaukee staff, and through social contacts from the 
Milwaukee area. One consideration in selecting respondents was to make sure that they knew what an assisted living facility is.

Educational level of the respondents ranged from 1 = grade school or some years at high school to $5=$ graduate degree $(s)$. The mean schooling was 3.4, which implies that the average level of education involved attending college or university. In terms of current employment status, $32 \%$ of the respondents were full time, $15 \%$ part-time employed, whereas $42 \%$ were retired. The remaining $10 \%$ were not employed at the time. Their occupations were quite variable, involving teachers, social workers, housewives, and so on. As for their living arrangements, an overwhelming majority of the respondents (91\%) were living in their own houses or apartments, some with their families or with health care service at home.

\section{Scales Used}

The data for the present article were collected as part of a larger questionnaire study about assisted living facilities. Apart from the measures explained below, data were obtained about demographic characteristics of the respondents (e.g., age, gender, educational status, current living arrangements, occupation, and current work status). The data considered in the present article involved four sections of the questionnaire: (a) free associations, (b) spatial-behavioral place descriptions, (c) visual place attributes, and (d) cognitive-affective place attributes. The latter section considered only assisted living, whereas the other sections involved assisted living, home, and nursing home, as further explained below. The sections were administered in the order noted above, starting with free associations for all respondents. Furthermore, in each section, participants responded first to assisted living, so that their responses might not be influenced by their answers to home and nursing homes, which then followed. This same order of the place types was used in all sections of the questionnaire, so that it would not be confusing for the older respondents. However, the items in spatialbehavioral place descriptions, visual place attributes, and cognitive-affective place attributes were presented in a standard random order, which was counterbalanced across respondents.

\section{Free-Association Task}

This task inquired about the attributes respondents freely associated with assisted living, home, and nursing home by asking them to list the properties or characteristics that they thought were associated with each place type. 


\section{Spatial-Behavioral Place Descriptions Scale}

This scale, developed for the present purposes, aimed to explore the degree to which homelike or institution-like spatial-behavioral place descriptions were associated with respondents' conceptions of assisted living, home, and nursing homes. The place descriptions used were selected on the basis of the literature related to living environments for older adults (e.g., Gubrium, 1975; Kane \& Wilson, 1993; Marsden, 1999; Schwarz \& Brent, 1999; Wilson, 1990; for a review, see Day, Carreon \& Stump, 2000). Some of this literature included studies that examine the homelike or institutional polarity (e.g., Marsden, 1999; Robinson, 1988; Robinson, Klensin, Bermudez, \& Johannes, 1992; Robinson, Thompson, Emmons, \& Graff, 1984).

Respondents were presented with five homelike and five institution-like spatial-behavioral place descriptions and asked to indicate the degree to which each description was similar to or different from their conceptions of assisted living, home, and nursing home. Responses were indicated on 5-point scales $(1=$ very similar, $5=$ very different $)$. Sample items involving homelike place descriptions are as follows: "In this place, if one desires to get away from others, it is possible ..."; ". . . residents have meals at a small table next to the kitchen ..."; ". . . one can make one's own schedules ..."; "This place has a range of furniture and decorations that reflect the tastes and personal histories ..."; and "In this place, the residents are personally engaged in familiar activities such as cooking and laundry." On the other hand, sample items for institution-like place descriptions are as follows: "In this place, residents are unable to go outdoors unaccompanied, or anytime they want ..."; "Because this place accommodates a large number of people, one might feel isolated ..."; “... going to one's bedroom requires walking through a long corridor with identical doors on both sides"; "... it is necessary to wake up and have breakfast at a scheduled time..."; and "... one feels uneasy while dressing because someone may suddenly open the door ..."

In the present study, Cronbach's alpha values for the homelike place descriptions were found to be $.75, .73$, and .66 for assisted living, home, and nursing home, respectively. The respective values for the institutionlike descriptions were $.73, .70$, and .84 . Hence, the scale seemed to have acceptable internal reliability for all the place types considered.

\section{Visual Place Attributes Scale}

This measure, developed by the author, consisted of two separate sets of photographs of interiors and exteriors (i.e., four interior and four exterior 
photographs that progressed from homelike to institution-like). When preparing this measure, a large pool of interior and exterior photographs of residential and institutional buildings, taken in the Milwaukee and Madison (Wisconsin) areas, served as the basis for selection of photographs shown in Figure 1. Possible distractions such as human figures and cars in some of the exterior photographs were digitally removed. Two groups of nine architects and/or environment behavior researchers from the School of Architecture at University of Wisconsin-Milwaukee served as judges in the selection and ranking of the photographs. One group participated in the selection of four interior and four exterior photographs to represent a gradation of homelike to institution-like properties. The second group then ranked the selected groups of photographs according to a scale of homelike to institution-like for validation of the representation and ranking. There was unanimous agreement among the judgments of the researchers involved on the homelike and institution-like ranking (i.e., homelike, somewhat homelike, somewhat institution-like, and institution-like) of both sets of photographs.

In the present study, respondents were asked to indicate the degree to which each photograph was similar to or different from their conceptions of assisted living, home, and nursing home. Again, responses were indicated on 5 -point scales $(1=$ very similar, $5=$ very different $)$.

\section{Cognitive-Affective Place Attributes Scale}

The aim of this scale, developed by the author for the present purposes, was to explore how assisted living was conceptualized in terms of the verbal (cognitive-affective) attributes that are considered important in the literature related to living environments for older adults (see Calkins \& Weisman, 1999; Day et al., 2000; Gubrium, 1975). For this purpose, 31 bipolar place descriptions were selected from the related literature. Some sample items may be the following: "would be a lively place or would not be a lively place"; "would not be a confusing place or would be a confusing place"; "would reflect the character(s) of its residents or would not reflect the character(s) of its residents"; "would be an informal place or would be a formal place"; "would be a private place or would be a public place"; "would have a warm feeling or would have a cold feeling." Respondents were asked to rate each item on a 5 -point scale $(1=$ very much agree with the left-side description, 2 = somewhat agree with the left-side description, $3=$ in between, $4=$ somewhat agree with the right-side description, $5=$ very much agree with the right-side description) according to their conceptions of assisted living. 


\section{Figure 1}

\section{Exterior and Interior Photographs Representing Homelike to Institution-Like Places of the Visual Place Attributes Scale}

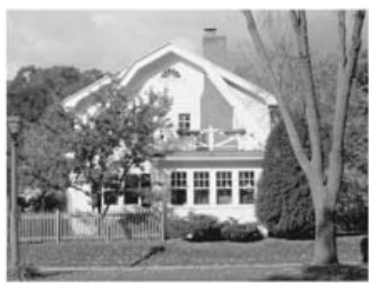

Ext - 1

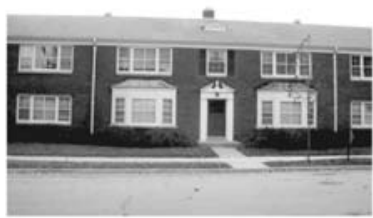

Ext - 2

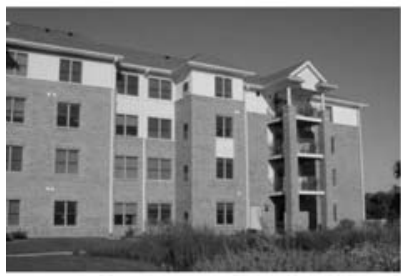

Ext - 3

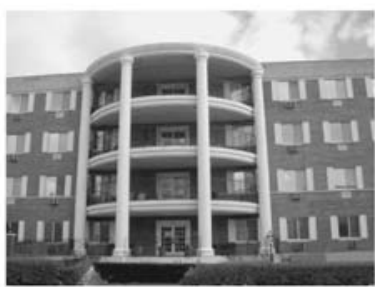

Ext - 4

(a)

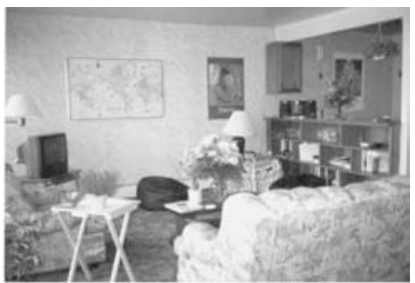

Int - 1

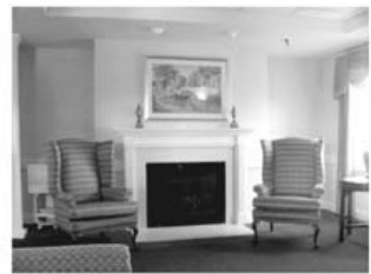

Int - 2

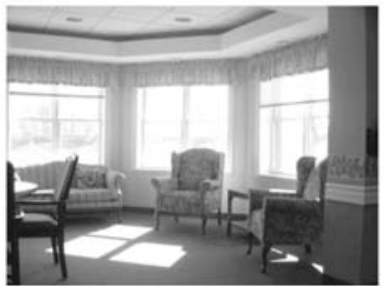

Int - 3

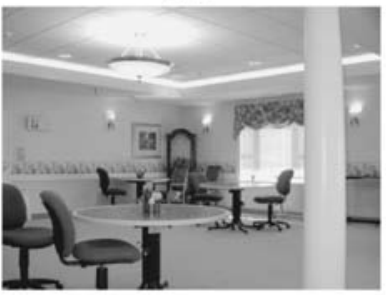

Int - 4

(b)

Note: Exterior 1 = homelike exterior : Exterior 2 = somewhat homelike exterior ; Exterior 3 = somewhat institution-like exterior; Exterior $4=$ institution-like exterior; Interior $1=$ homelike interior; Interior 2 = somewhat homelike interior; Interior 3 = somewhat institution-like interior; Interior 4 = institution-like interior. Respondents were asked to indicate the degree to which each photograph was similar to or different from their conceptions of assisted living, home, and nursing home using 5-point scales $(1=$ very similar, 5 = very different $)$. 


\section{Procedure}

Participation in the study was voluntary. Respondents were asked not to put their names on the questionnaires and were assured that their answers would be kept confidential. Nearly all respondents completed the questionnaire forms at their meeting places, offices, or homes by themselves. In rare instances, assistance was provided to certain older or disabled respondents to read the questions and to record their responses.

\section{Results}

First, the descriptive data from the Free Association Task are presented for assisted living, home, and nursing home. Then, analyses of variance (ANOVAs) results comparing the three place types in terms of spatialbehavioral and visual attributes are reported. Finally, the results of factor analysis conducted on the data involving cognitive-affective place attributes of assisted living are presented.

\section{Free Associates of Assisted Living, Home, and Nursing Home}

Descriptive data obtained from the Free Association Task consisted of characteristics freely associated with assisted living, home, and nursing home. In calculating the frequencies of attributes associated with each place type, only the different descriptors provided by each respondent (i.e., not repeats of the same descriptor, unless they were believed to fall under a different category) were considered. The overall percentage of agreement between initial groupings made by the author and those of two independent judges on a random sample of attributes was found to be $85 \%$ (7 to 8 disagreements out of approximately 50 attributes). Disagreements were discussed, and the groupings of the attributes were re-evaluated for the final classification.

As would be expected, home received the highest number of positive response items $(238 ; 74 \%)$ and few negative ones $(47 ; 15 \%)$. In contrast, nursing home received the highest number of negative response items (222; $64 \%)$, and very few positive ones $(9 ; 3 \%)$. On the other hand, assisted living was in between, much closer to home than nursing home with $105(32 \%)$ positive, and $57(17 \%)$ negative response items. The rest of the items consisted of neutral descriptive items such as, "help in home," "ramps and elevators." "hotel," "apartment-like living," "nurse on premises," "one room or 
suite," and so forth. No analyses were conducted on these data because the aim was to obtain descriptive information about the freely associated attributes of the three place types as summarized below.

Home. The most commonly reported attributes of home involved the attributes involving evaluation and affect (22\%, e.g., "warm," "cozy," "dignity"), control ( $21 \%$, e.g., independence, freedom control), comfort (13\%, e.g., "comfortable" and "relaxation"), sociality (12\%; $3 \%$ of which were negative references such as "isolation"), familiarity and personalization (9\%, e.g., familiar things, having personal items), stimulation and activities $(8 \%)$, safety and security (6\%), and privacy (5\%). Although home was generally conceived in very positive terms, there were also some references to difficulties of maintenance (e.g., chores, upkeep, and responsibility; "Chores that individual is unable to perform"), and to isolation (e.g., "may be lonely," "few visitors"). There were no references to other place types among the descriptors for home.

Nursing home. The most commonly reported attributes of nursing homes involved negative affect (26\%; e.g., "not to my liking," "depressing," "cold feelings," "loss of dignity," "anticipation of death"), lack of control (17\%; e.g., "dependence," "no freedom," "needing others' help"), lack of sociality (12\%; i.e., lack of social activities and interactions, isolation and loneliness), lack of flexibility (8\%), lack or loss of privacy (7\%), and the accessibility or mobility-related descriptors $(7 \%$; mostly referring to disability, wheelchairs). Also, some references were made to medical or health issues, management problems, and old age.

As noted above, responses related to nursing home were generally negative. However, a few respondents stated that for certain people, nursing homes were the only option and therefore, nursing home was seen to be an essential place type. Other than the essential function, there were very few positive attributes of place experience associated with nursing home (e.g., only a few respondents reported, "clean" and "pretty surroundings," whereas more mentioned "stinky" and "noisy"). Most of the small number of positive descriptors related to meals or medical issues were factual, referring mostly to the effectiveness of the provided care (e.g., "intense medical help available," "high level of care," and "meals served"). Some respondents also referred to other place types in their descriptions of nursing home (e.g., institution or institutional, hospital, dormitory or hotel). 
Assisted living. The most frequently reported associates of assisted living involved help care or control (18\%; e.g., "help if needed," "independence," or "some independence," "freedom," "some loss of control"), sociality (12\%; i.e., social interactions or social activities, or limited or lack of social interactions, isolation or loneliness, referred to by $4 \%$ of the respondents), evaluation or affect (i.e., positive responses such as "attractive," "pleasant," "very nice," 6\%, and negative responses such as "tasteless," "sad," "frustrating," "loss of dignity," 5\%), and stimulation or activities (5\%). References were also made to medical or health-related issues, old age, cost, and meals.

Somewhat similar to nursing homes, assisted living was also described by referring to other place types. Among those were references to home, hotel or dormitory, apartment, and nursing home. Inferring from the respondents' free responses in general, two different types of attitudes seemed to be held toward assisted living: those who saw it as a place type providing a lifestyle as close to independent living (i.e., "home") as possible and those who seemed to associate it with the negative reputation of nursing homes, and hence appeared to view it as a somewhat "good-looking" nursing home. However, most respondents seemed to be somewhere between these two viewpoints and seemed to regard assisted living as an essential improvement over nursing homes.

\section{Spatial-Behavioral Place Attributes of Assisted Living, Home, and Nursing Home}

Differences between mean similarity-difference ratings on the SpatialBehavioral Place Descriptions Scale for home, assisted living, and nursing home were compared using two separate one-way ANOVAs for homelike and institution-like place descriptions. Means for the three place types were significantly different for both the homelike descriptions index, $F(2,194)=$ 253.51, $p<.001$, and the institution-like descriptions index, $F(2,194)=$ $310.96, p<.001$. As expected, homelike descriptions were seen as being similar to respondents' conceptions of homes $(M=1.79, S D=.88)$ and different from those of nursing homes $(M=4.30, S D=.67)$, whereas assisted living was rated in between $(M=2.44, S D=.85)$ but more similar to a homelike place. In contrast, institution-like descriptions were seen as similar to nursing homes $(M=1.84, S D=.90)$ and different from homes $(M=4.62, S D=.55)$, whereas assisted living $(M=3.21, S D=.88)$ was rated in between. Follow-up analyses involving the Tukey technique indicated all the differences between 
the means to be significant at least at the .01 level. Thus, as highlighted in Figure 2a, home and nursing home were characterized in opposite terms, whereas assisted living was conceived in between, as a distinct place type significantly different from both home and nursing home but as having more homelike than institution-like spatial-behavioral characteristics.

\section{Visual Place Attributes of Assisted Living, Home, and Nursing Home}

Data obtained on the Visual Place Attributes Scale for home, assisted living, and nursing homes were analyzed by separate ANOVAs. The first question considered was how home and nursing home were rated in terms of the interior and exterior sets of four photographs, to verify that the photographs were perceived as intended, and then to explore how assisted living was represented visually. As shown in Table 1, significant ANOVA results (shown in columns) involving home indicated that, in congruence with the judges' evaluations, homelike interior (Interior 1) and exterior (Exterior 1) photographs were perceived as being most similar to a home, whereas the institution-like photographs (Interior 4 and Exterior 4) were rated as being most different, with the "somewhat homelike" and "somewhat institutionlike" interior and exterior photographs being in between. On the other hand, for nursing homes, a similar gradation, in reverse order, was obtained; the photographs of institution-like interiors (Interior 4) and exteriors (Exterior 4) being rated as most similar and the homelike interior (Interior 1) and exterior (Exterior 1) photographs being rated as most different (Table 1). Thus, separate ANOVA results for home and nursing home pertaining to differences across the four interior or exterior photographs revealed that the photographs were perceived as would be expected, except that (according to follow-up analyses using the Tukey test) the differences involving the middle exterior photographs (i.e., Exterior 2 vs. Exterior 3, and Exterior 3 vs. Exterior 4) did not reach significance for home ratings, although the trend was in the expected direction. Hence, in general, the significant gradations received for the ratings of home and nursing home may be said to provide evidence for the validity of the photographs used.

Unlike home and nursing home, for which systematic gradations of similarity-difference ratings were obtained for homelike or institution-like photographs, the related ratings for assisted living did not reveal such a gradation. In fact, as can be seen in Table 1, mean similarity measures of assisted living did not show a significant differentiation regarding the 
Figure 2

Mean Homelike and Institution-Like Ratings for Home, Assisted Living Facilities (ALF), and Nursing Home (NH) Obtained (a) Using the Spatial-Behavioral Place Descriptions Scale, (b) Using the Visual Place Attributes Scale for Exteriors, and (c) for Interiors
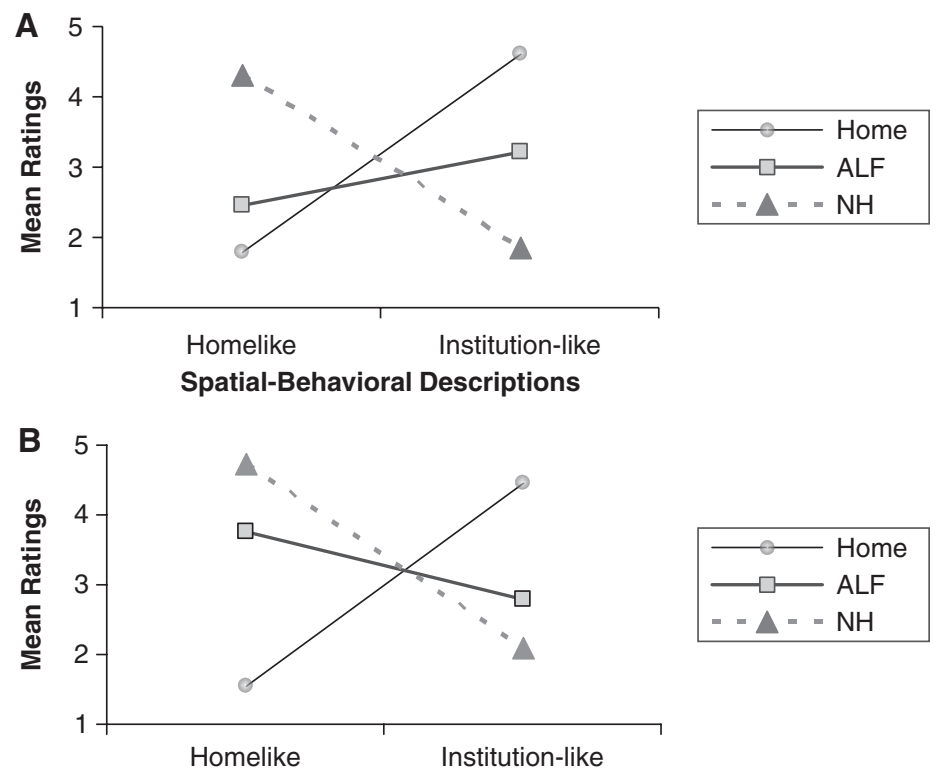

Exterior Photographs
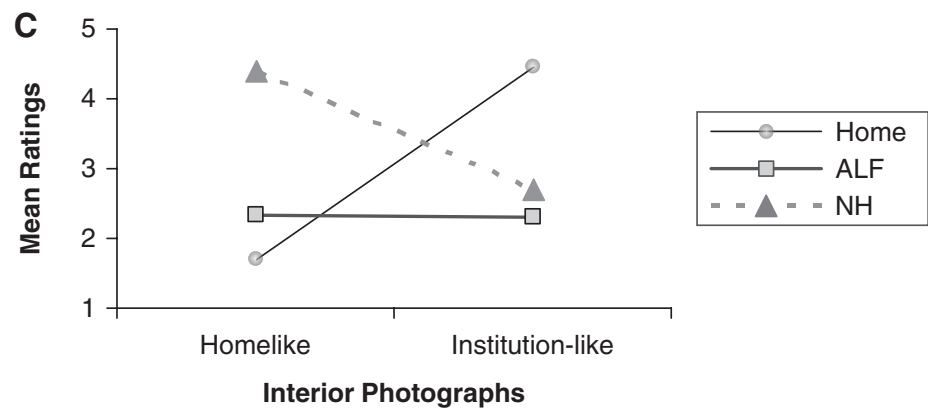

Note: $1=$ very similar, $5=$ very different . 
Table 1

Differences Between Mean Ratings for Home, Assisted Living Facilities, and Nursing Homes Involving the Visual Place Attributes Scale

\begin{tabular}{|c|c|c|c|c|c|c|c|}
\hline Photographs & Home & $S D$ & ALF & $S D$ & $\mathrm{NH}$ & $S D$ & $F^{\mathrm{a}}$ \\
\hline \multicolumn{8}{|l|}{ Exterior } \\
\hline $\begin{array}{l}\text { Homelike } \\
\quad(\text { Exterior 1) }\end{array}$ & $1.54_{\mathrm{a}}$ & 1.12 & $3.75_{b}$ & 1.38 & $4.74_{c}$ & 0.66 & $228.15^{*}$ \\
\hline $\begin{array}{l}\text { Somewhat } \\
\text { homelike } \\
\text { (Exterior 2) }\end{array}$ & $3.59_{\mathrm{a}}$ & 1.40 & $2.30_{\mathrm{b}}$ & 1.11 & $3.47_{\mathrm{a}}$ & 1.33 & $26.80 *$ \\
\hline $\begin{array}{l}\text { Somewhat } \\
\text { institution-like } \\
\text { (Exterior 3) }\end{array}$ & $4.17_{\mathrm{a}}$ & 1.27 & $2.65_{b}$ & 1.30 & $2.57_{b}$ & 1.44 & $41.33^{*}$ \\
\hline $\begin{array}{l}\text { Institution-like } \\
\text { (Exterior 4) }\end{array}$ & $4.44_{a}$ & 1.07 & $2.79_{b}$ & 1.41 & $2.09_{c}$ & 1.33 & $79.21 *$ \\
\hline$F^{\mathrm{b}}$ & $139.71 *$ & & $23.86^{*}$ & & $112.46^{*}$ & & \\
\hline \multicolumn{8}{|l|}{ Interior } \\
\hline $\begin{array}{l}\text { Homelike } \\
\quad(\text { Interior 1) }\end{array}$ & $1.70_{\mathrm{a}}$ & 1.17 & $2.33_{\mathrm{b}}$ & 1.07 & $4.38_{c}$ & 0.97 & $152.20 *$ \\
\hline $\begin{array}{l}\text { Somewhat } \\
\text { homelike } \\
\text { (Interior 2) }\end{array}$ & $2.33_{\mathrm{a}}$ & 1.34 & $2.49_{\mathrm{a}}$ & 1.13 & $3.92_{\mathrm{b}}$ & 1.23 & $57.47 *$ \\
\hline $\begin{array}{l}\text { Somewhat } \\
\text { institution-like } \\
\text { (Interior 3) }\end{array}$ & $3.47_{\mathrm{a}}$ & 1.44 & $2.22_{\mathrm{b}}$ & 1.11 & $3.11_{\mathrm{a}}$ & 1.45 & $21.32 *$ \\
\hline $\begin{array}{l}\text { Institution-like } \\
\text { (Interior 4) }\end{array}$ & $4.45_{\mathrm{a}}$ & 0.95 & $2.30_{\mathrm{b}}$ & 1.11 & $2.69_{b}$ & 1.47 & $83.17 *$ \\
\hline$F^{\mathrm{b}}$ & $115.82 *$ & & 1.30 & & $46.35^{*}$ & & \\
\hline
\end{tabular}

Note: ALF = assisted living facilities; $\mathrm{NH}=$ nursing homes; Higher means indicate greater difference of the photograph from the related place type (i.e., home, assisted living facilities, and nursing homes; 1 = very similar to place type, $5=$ very different from place type). Means in the same row that do not share a common subscript are significantly different from each other at least at the .01 level according to the Tukey test.

a. Degrees of freedom $=2$ and 194.

b. Degrees of freedom $=3$ and 291.

$* p<.001$.

homelike or institution-like interior photographs. That is, both the homelike and the institution-like interiors were perceived to be similarly representative of assisted living. On the other hand, in terms of the exterior photographs, 
assisted living was conceived to be less similar to homelike than institutionlike photographs (i.e., relative to a homelike exterior, assisted living was conceived to have a relatively more institution-like exterior; Table 1).

A second set of ANOVAs were conducted to explore whether home, nursing home, and assisted living were rated differently in terms of each photograph. As shown in Table 1, all analyses (shown in the rows) involving differences between assisted living, home, and nursing home for each photograph yielded significant results. Follow-up analyses using the Tukey tests indicated that home and nursing home were rated as being significantly different in the expected direction in all photographs, except the "somewhat homelike" exterior (Exterior 2) and the "somewhat institution-like" interior (Interior 3) photographs, for which the related differences did not reach significance. Respondents perceived both photographs (i.e., Exterior 2 and Interior 3) to be somewhat different from both home and nursing home.

As shown in Table 1, the visual exterior representation of assisted living seemed to be differentiated from that of home for each photograph. Similarly, the exterior representation of assisted living was significantly differentiated from nursing home in all but the "somewhat institution-like" exterior (Exterior 3) photograph. Thus, in terms of the exterior photographs, assisted living was generally conceived to be in between home and nursing home, being significantly different from (except for the "somewhat institution-like" exterior, i.e., Exterior 3, photograph) but closer to nursing home than home.

On the other hand, in terms of the interior photographs, as shown in Table 1, assisted living was conceived as being more similar to a home than a nursing home on the homelike photographs; in fact, mean rating of assisted living did not differ significantly from that of home on the "somewhat homelike" interior photograph (Interior 2). On the "institution-like" interior photograph (Interior 4), mean rating for assisted living differed significantly from that of home but was not different from that of nursing home, whereas it differed from both place types on the "somewhat institutionlike" interior photograph (Interior 3). Thus, both the homelike and the institution-like interior photographs seemed to be "somewhat similar" to assisted living.

The differences between the visual representations of the three place types are highlighted in Figure $2 b$ and $2 c$, in which only differences involving the homelike and institution-like interior and exterior photographs are considered in parallel to the spatial-behavioral representations reported above. 


\section{Factor Analysis of the Data From the Cognitive-Affective Place Attributes Scale Involving Assisted Living}

A varimax rotated factor analysis was conducted on the data from the Cognitive-Affective Place Attributes Scale, involving 31 attribute items, to determine the basic dimensions of the attributes of assisted living. As shown in Table 2, the analysis yielded four factors, with eigenvalues greater than 1 , which explained $67 \%$ of the total variance.

The first factor, labeled homeyness, explained $25 \%$ of the total variance and had an eigenvalue of 7.71. As can be seen in Table 2, the items that loaded on this factor were associated with such attributes as flexible, informal, comfortable, ease of obtaining privacy, homelike, reflecting personal histories, warm (feeling), private, voluntary, free choice, pleasant, feelings of control, and reflecting characters of residents. It was the strongest factor associated with a favorable evaluation. The alpha value of the resulting scale was .96 .

The second factor, labeled stimulation-freedom, had an eigenvalue of 4.91 and explained $16 \%$ of the total variance. The items that loaded on this factor were associated with having stimulating elements, regarding time spent there as worthwhile, lively, personalized, being able to get away from others, aesthetics, and freedom of action (Table 2). The alpha value of the resulting scale was .91 .

The third factor was labeled the security-control factor. It explained $14 \%$ of the total variance and had an eigenvalue of 4.46. As shown in Table 2 , this factor was associated with items referring to security, safety, and control of one's environment. The related alpha value was .87.

The fourth factor of social interaction explained $12 \%$ of the total variance and had an eigenvalue of 3.71. The items that loaded on this factor were associated with the ease of social interaction. The alpha value of the resulting scale was .84 .

The means for the four factors were $2.38,2.27,1.97$, and 2.02 , respectively. Those mean values indicated that the respondents, in general, somewhat agreed that assisted living can be represented in terms of attributes associated with homeyness, stimulation-freedom, security-control, and social interaction. Correlations between those four factors varied between .80 and .72 , all being highly significant at the .001 level. In fact, a second order factor analysis, using mean factor scores of the first factor analysis as variables, yielded a single factor, labeled general evaluation of assisted living, which had an eigenvalue of 3.29 and explained $82.34 \%$ of the total variance (factor loadings varied between .91 and .89 ). The Cronbach's alpha of the related scale was .93 . 


\section{Table 2}

\section{Factor Analysis of the Data From the}

\section{Cognitive-Affective Place Attributes Scale}

\begin{tabular}{|c|c|c|}
\hline Factor (67.06\% Explained Variance) & Loading & Communality \\
\hline \multicolumn{3}{|l|}{ Factor 1: Homeyness (24.88 \%) } \\
\hline Flexible & .74 & .76 \\
\hline Informal & .73 & .68 \\
\hline Comfortable & .72 & .78 \\
\hline Obtaining privacy & .71 & .76 \\
\hline Homelike & .70 & .71 \\
\hline Reflecting personal histories & .70 & .50 \\
\hline Warm (feeling) & .70 & .74 \\
\hline Private & .67 & .73 \\
\hline Voluntary & .67 & .64 \\
\hline Free choice & .64 & .62 \\
\hline Pleasant & .63 & .74 \\
\hline (Feeling in) control & .59 & .71 \\
\hline Reflecting characters of residents & .50 & .59 \\
\hline \multicolumn{3}{|l|}{ Factor 2: Stimulation-freedom $(15.85 \%)$} \\
\hline Stimulating elements & .77 & .68 \\
\hline Regarding time spent as worthwhile & .70 & .68 \\
\hline Lively & .67 & .67 \\
\hline Personalized & .61 & .79 \\
\hline Being able to get away from others & .59 & .61 \\
\hline Aesthetics & .56 & .71 \\
\hline Freedom of action & .49 & .62 \\
\hline \multicolumn{3}{|l|}{ Factor 3: Security-control (14.37\%) } \\
\hline Security & .81 & .72 \\
\hline Safety & .75 & .81 \\
\hline Livable & .57 & .70 \\
\hline Not crowded & .57 & .64 \\
\hline Not confusing & .48 & .59 \\
\hline Being able to go in and out as one pleases & .46 & .47 \\
\hline \multicolumn{3}{|l|}{ Factor 4: Social interaction $(11.96 \%)$} \\
\hline Ease of social interaction & .83 & .77 \\
\hline Feeling free to participate in activities & .66 & .68 \\
\hline Wayfinding & .58 & .57 \\
\hline Facilitating comfortable conversation & .48 & .61 \\
\hline Supportive & .47 & .52 \\
\hline
\end{tabular}

\section{Discussion}

As expected, results indicated that home and nursing home are generally represented as opposing place types on the homelike and institution-like 
dimensions and that assisted living is conceived as a distinct place type in between but with more homelike than institution-like attributes in general. Specifically, results of the Free Association Task, Spatial-Behavioral Place Descriptions Scale, and the Cognitive-Affective Place Attributes Scale suggested that respondents generally had favorable representations of assisted living. For instance, the factor analysis of the data from the CognitiveAffective Place Attributes Scale indicated that respondents in general conceived assisted living in terms of attributes associated with homeyness, stimulation-freedom, security-personal control, and opportunities for social interaction, all of which referred to a favorable general evaluation. Hence, results from different sections of the study involving verbal attributes provided converging evidence that assisted living was generally represented in favorable rather than unfavorable terms. This favorable representation of assisted living is consistent with results of other related studies on assisted living (e.g., Ball et al., 2000; Brummett, 1997; Dobbs, 2004; C. Imamoğlu \& Imamoğlu, in press; Regnier, 1994; Wilson, 1990; Zavotka \& Teaford, 1997).

Results also implied several suggestions for an understanding of how assisted living as a new place schema is represented relative to the older schemata of home and nursing homes. First, results suggested that new place schemata may develop in terms of differences from or similarities with the already existing place schemata. For instance, in the Free Association Task, respondents did not refer to any other place type when describing their conceptions of home, which is likely to be represented as a well-established schema and referred to only a few other places with regards to nursing homes, but they referred to various place types, particularly to home and nursing home, when describing their conceptions of assisted living. Respondents who appeared to hold favorable views of assisted living seemed to represent it as a more homelike and less institution-like place, whereas those with an unfavorable outlook appeared to view it in opposite terms. Other related findings from the project, of which the present study is a part, suggested that a favorable assisted living schema seems to develop by associations with the home schema and dissociations with the nursing home schema (C. Imamoğlu, 2002). For instance, increased familiarity with assisted living was found to predict a more favorable homelike representation of assisted living, which was negatively associated with an institutional representation (C. Imamoğlu \& Imamoğlu, in press). Those findings suggest that the more people become familiar with assisted living, the more strengthened may be its associations with the home schema and weakened with the nursing home schema. 
Second, in line with the social cognition literature (Fiske \& Taylor, 1991), results suggested that the different types of attributes of the newly emerging assisted living schema may be less consistently organized than those of the older place types of home and nursing home. Both spatialbehavioral and visual representations were consistent with each other in representations of home and nursing homes as homelike and institution-like places, respectively. On the other hand, as noted above, results involving the spatial-behavioral attributes, the cognitive-affective place attributes, and the free associates implied that assisted living was represented more as a homelike than an institution-like place. In contrast, results regarding the visual place attributes suggested that it was seen as being rather institutionlike in the exterior and undifferentiated in terms of its interior. Thus, results indicated that, unlike home and nursing home, which appeared to have differentiated visual representations, assisted living did not seem to show a clear visual differentiation on the homelike-institution-like dimension, especially for representations of interiors, indicating that there is not a consensus on what an assisted living facility should look like in general.

If such inconsistencies do not reflect the reality of assisted living, as a hybrid between home and institution-like places, they may imply that different types of attributes (i.e., verbal and visual) of a newly developing place schema may not be as consistently linked with each other as those of the well-established place schemata. Those results may be supportive of an interactive process model of newly emerging place types suggested by C. Imamoğlu (2002), which asserts that meaning of a place is created before its physical form. Accordingly, conceptions of new place types may be initiated by the meaning-related cognitive-affective attributes first and then proceed with the visual attributes involving form, only later in time. On the other hand, in the well-established schemata, for instance, of home, visual representation or form may even serve as the label for the meaning of home (similarly for a school, church, mosque, etc.), such that it may be difficult to separate them in our conceptualization. In this regard, the relationship of the visual form, and especially the exterior form, to the function or meaning of a place type may be likened to an outfit or uniform for an occupation. Function and its related attributes and expectations may exist irrespective of the type of uniform or visual representation (i.e., they are not inevitably linked); for instance, a police officer would still be a police officer in regular clothing, but once we learn to associate that profession with a particular outfit, then the uniform (or visual image) acts as a cue or label for that profession (or function or meaning). Hence, in the case of well-established professional groups (or 
place types), uniforms (i.e., visual images) tend to be amalgamated with the related schemata. However, for new professions or place types, people may not have developed clearly differentiated prototypic visual representations yet. Instead, as in the case of assisted living, they might be referring to various specific cases they have been exposed to (or exemplars). These suggestions need to be explored in future studies.

A final observation was that the affective tone of the respondents' associates for both home and nursing home appeared to be stronger relative to assisted living. For instance, nursing home seemed to have a rather negative image in people's minds, reflected also by the high number of negative affective attributes freely reported. Some of the attributes written by the respondents included such negative responses as "very depressing," "place not wanting to be, noxious odors," "sharing a room with a total stranger, crying and moaning," "anticipation of death, cold, and unhealthy feelings," "stinky," "final stop before death when ill," "crowded," "people sitting alone in their wheelchairs," "very limited ability to decorate to personal tastes," "inability to leave premises-feel like a prisoner," "expense, despair, depression," "no privacy, too structured," "no independence," "humiliating, degrading," and so forth. Although associated with nursing home by some respondents, assisted living, in fact, appeared to be recognized as distinct from nursing home and was represented in more favorable terms by most of the respondents, as noted above. For instance, some references to assisted living facilities involved such responses as "good for elderly," "disable but not unable, some independence, peace of mind," "second best if you need help," "almost like home with need of some help," "between home and nursing home setting, moderate amount of privacy," "ideal for those who need monitoring," "social atmosphere," "homelike place, part of a "family', independent schedule," "pleasant surrounding," "privacy, security, safety"; with relatively few negative responses such as "boring," "sad," "expensive," and so forth. Not only were the references to assisted living more favorable than those of nursing homes but also their affective tone appeared to be more moderate than those for nursing homes. Hence, it is suggested that affect triggered by newly emerging schemata, such as the place schema for assisted living, may be weaker than that triggered by the well-established home and nursing home schemata. Those observations may suggest that respondents, who probably were still in the learning phase regarding assisted living, might not have developed strong feelings for it yet but might have been trying to modify their existing place schemata of assisted living by comparisons with better known place types, such 
as "between home and nursing home," "almost like home ..." or "apartment-like living." Accordingly, they appeared to be more likely to refer to assisted living by less affective but functional descriptors such as, "you have assistance with things you cannot do well," "help in home," "prepared meals," "cleaning done," and so forth.

As noted by an anonymous reviewer, it should also be mentioned that the affective connotations of the three place types may be a reflection of the respondents' feelings about health versus disability and the dying process. In general, people living at home tend to be healthier or more functional than those in assisted living; people in assisted living facilities tend to be healthier than those in nursing homes, who in general tend to be more dependent, and in fact, closer to death, as the respondents mentioned in the Free Association Task noted above. Hence, in the words of the reviewer, "How respondents feel about the healthy-disabled continuum may be impacting their impression of the setting more than anything else."

Before concluding, some limitations of the study need to be considered. First, as has been noted, a convenience sample was used in the survey, which was necessitated by problems of access to respondents and the respondents' ability and willingness to participate in the study. Therefore, one needs to be cautious in generalizing the results to the larger population. To further explore the generalizability of the findings, future studies can explore possible variations in the responses of, for instance, social workers working with older adults or samples from different cultures with different outlooks toward old age and institutional living. Future studies can also explore the degree to which the present findings can be generalized to schemata regarding other new place types, such as cohousing, cyber cafes, and so forth.

In the present study, data regarding the Cognitive-Affective Place Attributes Scale were obtained only for assisted living because of concerns about the length of the questionnaire and the attention span of the respondents. Future studies may compare assisted living with the other related place types on those dimensions. Furthermore, although converging evidence was obtained for homelike and institution-like visual representations of the place types considered in the present study, future studies might be advised to explore visual representations using a larger number of homelike and institution-like photographs. Finally, it might also be interesting to explore how people's schemata of assisted living or other new place schemata change with time. 


\section{References}

The Assisted Living Workgroup. (2003). Assuring quality in assisted living. Guidelines for federal and state policy, state regulation, and operations (A report to the U.S. Senate Special Committee on Aging). Retrieved March 30, 2006, from http://www.aahsa.org/ alw.htm

Ball, M. M., Whittington, F. J., Perkins, M. M., Patterson, V. L., Hollingsworth, C., King, S. V., et al. (2000). Quality of life in assisted living facilities. Journal of Applied Gerontology, 19, 304-325.

Brummett, W. (1997). The essence of home: Design solutions for assisted living housing. New York: Van Nostrand Reinhold.

Calkins, M. P., \& Weisman, G. D. (1999). Models for environmental assessment. In B. Schwarz \& R. Brent (Eds.), Aging, autonomy, and architecture: Advances in assisted living (pp. 130-140). Baltimore: The Johns Hopkins University.

Day, K., Carreon D., \& Stump, C. (2000). The therapeutic design of environments for people with dementia: A review of the empirical research. Gerontologist, 40, 397-416.

Dobbs, D. (2004). The adjustment to a new home. Journal of Housing for the Elderly, 18, 51-71.

Fiske, S. T., \& Taylor, S. E. (1991). Social cognition (2nd ed.) New York: McGraw-Hill.

French, E. M., \& Mosher-Ashley, P. M. (2000). College students' attitudes toward residential care facilities. Educational Gerontology, 26, 583-603.

Gubrium, J. F. (1975). Living and dying at Murray Manor. New York: St. Martin's.

Imamoğlu, C. (2002). Toward an understanding of place schema: Societal and individuallevel representations of assisted living. Unpublished doctoral dissertation, University of Wisconsin-Milwaukee.

Imamoğlu, C., \& Imamoğlu, E. O. (in press). Relationship between familiarity, attitudes and preferences: Assisted living facilities as compared to nursing homes. Social Indicators Research.

Imamoğlu, E. O., \& Imamoğlu, V. (1992). Life situations and attitudes of the Turkish elderly toward institutional living within a cross-cultural perspective. Journal of Gerontology: Psychological Sciences, 47, 102-108.

Imamoğlu, E. O., \& Kılıç, N. (1999). A social psychological comparison of the Turkish elderly residing at high or low quality institutions. Journal of Environmental Psychology, 19, 231-242.

Johnson, C. L., \& Grant, L. A. (1985). The nursing home in American society. Baltimore: Johns Hopkins University Press.

Kane, R. A. (2001). Long-term care and a good quality of life: Bringing them closer together. Gerontologist, 41, 293-304.

Kane, R. A., \& Wilson, K. B. (1993). Assisted living in the United States: A new paradigm for residential care for frail older persons? Washington, DC: American Association of Retired Persons.

Marsden, J. P. (1999). Older persons' and family members' perceptions of homeyness in assisted living. Environment and Behavior, 31, 84-106.

Mollica, R. L., Wilson, K. B., Ryther, B. S., \& Lamarche, H. J. (1995). Guide to assisted living and state policy. Minneapolis: University of Minnesota.

Regnier, V. (1994). Assisted living housing for the elderly: Design innovations from the United States and Europe. New York: Van Nostrand Reinhold.

Robinson, J. W. (1988). Institution and home: Linking physical characteristics to perceived qualities of housing. In H. van Hoogdalem, N. Prak, R. van der Voordt, \& H. van Wegen 
(Eds.), Proceedings of the 10th Conference of the International Association for the Study of People and Their Physical Surroundings: Vol. 2. Looking back to the future / Se retourner vers l'avenir (pp. 431-440). Delft, the Netherlands: Delft University Press.

Robinson, J. W., Klensin J., Bermudez, J., \& Johannes, M. (1992). Probing terminology for cultural categories: Institution and home. In A. Arisitidis, C. Karaletsou, \& K. Tsoukala (Eds.), Socio-environmental metamorphoses: Proceedings of the 12th Conference of the International Association for the Study of People and Their Physical Surroundings (pp.180-189). Chalkidikik, Greece: Aristotle University Press.

Robinson, J. W., Thompson, T., Emmons, P., \& Graff, M. (1984). Towards an architectural definition of normalization: Design principles for housing severely and profoundly mentally retarded adults. Minneapolis: University of Minnesota.

Schwarz, B. (1999). Assisted living: An evolving place type. In B. Schwarz \& R. Brent (Eds.), Aging, autonomy, and architecture: Advances in assisted living (pp. 185-206). Baltimore: Johns Hopkins University Press.

Schwarz, B., \& Brent, R. (Eds.). (1999). Aging autonomy and architecture: Advances in assisted living. Baltimore: Johns Hopkins University Press.

Steinhauer, J. (2001, February 12). As assisted living centers boom, calls for regulation are growing. New York Times, p. A1.

Wilson, K. B. (1990). Assisted living: The merger of housing and long term care services. Long Term Care Advances, 1, 2-8.

Zahn, M. (2001, August 26). Lapses lead to deaths in assisted living care. Milwaukee Journal Sentinel, p. 1A.

Zavotka, S. L., \& Teaford, M. H. (1997). The design of shared social spaces in assisted living residences for older adults. Journal of Interior Design, 23, 2-16.

Zimmerman, S. I. (2000). Policies and practices in assisted living. The Gerontologist: 53rd Annual Scientific Meeting. Linking Research to Policy, Practice, and Education: Lessons Learned, Tasks Ahead, 40, 209-210.

Çağrı Imamoğlu is an assistant professor in Department of Interior Architecture and Environmental Design at Bilkent University, Turkey. He received his PhD in architecture from University of Wisconsin-Milwaukee in 2002. His research interests include environmental cognition and evaluation, environments for older adults, and design education. 